\title{
Vector Genomes per Milliliter
}

National Cancer Institute

\section{Source}

National Cancer Institute. Vector Genomes per Milliliter. NCI Thesaurus. Code C124472.

A unit for cloning vector amounts expressed as the number of vector genomes per

milliliter. 